\title{
Anthelmintic resistance status of gastrointestinal nematodes of sheep to the single or combined administration of benzimidazoles and closantel in three localities in Mexico
}

Yazmin Alcalá-Canto' 1 0000-0001-7809-392X

Luis Ocampo Camberos ${ }^{2}$ Héctor Sumano López ${ }^{2}$ Lilia Gutiérrez Olvera ${ }^{2 *}$ Graciela Tapia Pérez ${ }^{3}$

'Departamento de Parasitología ${ }^{2}$ Departamento de Fisiología y Farmacología ${ }^{3}$ Departamento de Genética y Bioestadistica Facultad de Medicina Veterinaria y Zootecnia Universidad Nacional Autónoma de México Av. Universidad 3000, Delegación Coyoacán Ciudad de México C.P. 04510

*Corresponding author: Tel: + (52) 5556225908 ext: 108

Email address:

liliago@unam.mx
Received: 2016-04-19 Accepted: $\quad 2016-11-10$

Published: $\quad 2016-12-07$

Additional information and declarations can be found on page 8

@ Copyright 2016 Yazmin Alcalá-Canto et al.

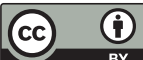

Distributed under Creative Commons CC-BY 4.0

\section{Abstract}

Sheep production requires the constant assessment of parasitic burden and the efficacy of existing treatments for proper management. In this study, the administration of five different treatments was evaluated for the reduction of the percentage of eggs per gram of feces (EPG) shed by gastrointestinal nematodes (GIN) from sheep on three different sheep-breeding farms in Mexico (Texcoco, Estado de Mexico; Hueytamalco, Puebla; and Tlaltizapán de Zapata, Morelos). In these farms, ivermectin and benzimidazole derivatives had been routinely administered for two consecutive years. To determine whether drugs with different pharmacological properties decreased GIN fecal egg excretion, the treatments closantel (CLOS), albendazole (ABZ) and fenbendazole (FBZ) were administered alone and in combinations of $\mathrm{CLOS}+\mathrm{ABZ}$ and $\mathrm{CLOS}+\mathrm{FBZ}$, to five groups of sheep, with an additional untreated control group on each farm ( $n=28$ per flock). Anthelmintic resistance was determined using Fecal Egg Count Reduction Tests (FECRT) as recommended in the guidelines of the World Association for the Advancement of Veterinary Parasitology. Fecal samples were collected 14 and 21 days after treatment. The anthelmintic resistance status was determined based on the reduction in the fecal egg count arithmetic mean and $95 \%$ confidence limits. According to the FECRT, resistance developed to CLOS, $A B Z$, FBZ and CLOS + FBZ because the mean percentage of EPG reduction was $\leq 95 \%$ with a lower confidence limit of $\leq 90 \%$. By contrast, nematode susceptibility was confirmed for the CLOS + ABZ combination, as it reduced the percentage of GIN fecal egg output by $96.46 \pm 3.04 \%$ (day 14) and $96.88 \pm 3.04 \%$ (day 21). Based on the morphometric identification of larvae, Haemonchus spp., Cooperia spp. and Teladorsagia spp. were the most abundant genera on all farms before the administration of these five treatments. In conclusion, the use of the anthelmintic combination of closantel plus albendazole may reduce the development of anthelmintic resistance in gastrointestinal nematodes.

Keywords: albendazole, fenbendazole, closantel, sheep, nematodes, resistance. 


\section{Introduction}

Gastrointestinal parasites cause substantial health problems that undermine the production of grass-feeding ruminants. Parasites of the superfamily Trichostrongyloidea, particularly Haemonchus contortus and Teladorsagia circumcincta, impair productivity in sheep and goat-producing regions in tropical and temperate regions ${ }^{1,2}$. Control of these parasites has relied primarily on the intensive use of anthelmintic drugs such as benzimidazole drugs (BZ), primarily albendazole, oxfendazole, and fenbendazole; macrocyclic lactones such as ivermectin and imidazothiazole; and tetrahydropyrimidine derivatives such as levamisole and morantel-tartrate ${ }^{3}$. Nevertheless, with the continuous use of these anthelmintic drugs, anthelmintic resistance (AR) has developed in parasites ${ }^{4-10}$. In particular, the anthelmintic resistance AR of gastrointestinal nematodes (GIN) in sheep occurs globally and is described as a major threat to sheep production ${ }^{11}$, 12. For example, gastrointestinal nematodes were resistant to benzimidazole on all farms assessed with a previous history of benzimidazole use in ithuanian sheep ${ }^{13}$, and in many flocks in India (14). Moreover, AR reaches high levels in Asia, Latin America, Africa, Australia, and New Zealand, in addition to regions that rely on small ruminants as one of the primary sources of animal protein ${ }^{4-10}$. In Mexico, low resistance to benzimidazole was demonstrated in southeastern Mexico in 2003, but the authors warned that resistance could increase due to the continuous use of benzimidazole derivatives ${ }^{15}$. The warning was accurate, and AR in grazing ruminants is currently increasing in Mexico 7, 8, 16. For the prevention and management of $A R$, important considerations are the frequency of the development of anthelmintic drug resistance and the extent at which it spreads ${ }^{17}, 18$. In particular, for the benzimidazole derivatives used in sheep, the evaluation of their efficacy or the resistance to them is of paramount importance for the timely management of gastrointestinal nematodes ${ }^{14}$.

While studies on the mechanisms of AR indicate that the use of antiparasitic drugs that are in different chemical groups delays the selection of resistant nematodes $1,19,20$, Haemonchus spp. and Trichostrongylus spp. from sheep in Brazil have developed simultaneous resistance to albendazole, ivermectin, levamisole, moxidectin, and closantel ${ }^{21}$. Multiple-anthelmintic resistance has also been reported in major sheep producing countries, such as Australia and New Zealand, and in various South American regions ${ }^{1}$. Nevertheless, information is not available on the combined effects of benzimidazole drugs plus closantel to treat herds with resistant gastrointestinal nematodes. Therefore, in this study, we assessed the anthelmintic resistance of gastrointestinal nematodes in sheep treated with closantel (CLOS), albendazole (ABZ), fenbendazole (FBZ) and the combinations of $\mathrm{CLOS}+\mathrm{ABZ}$ and $\mathrm{CLOS}+\mathrm{FBZ}$, in three different locations in Mexico.

\section{Materials and methods}

The study was conducted on sheep farms in three different states in Mexico during the rainy season. Farm (A) was in Texcoco, Estado de Mexico, which is a region classified as a temperate wet climate with an annual mean temperature of $15.2^{\circ} \mathrm{C}$. Farm (B) was in Hueytamalco, Puebla, which has a subtropical climate, no dry 
season and an annual mean temperature of $20.0^{\circ} \mathrm{C}$. Farm (C) was in Tlaltizapán de Zapata, Morelos, which has a subtropical wet climate and an annual mean temperature of $23.5^{\circ} \mathrm{C}$.

\section{Animals and study design}

The design of the study was a two-factor complete block experiment. The study adhered to the guidelines of the Institutional Committee for Use and Care of Experimental Animals of the Universidad Nacional Autónoma de México (UNAM). On the three sheep farms, namely, farms A (Mexico State), B (Puebla State) and C (Morelos State), more than 200 crossbred sheep were reared under a semi-extensive system in which the animals graze in paddocks for approximately 10 hours during the day and are penned for the night. These farms have a long history of GIN, and ivermectin and benzimidazole derivatives have been routinely administered for two consecutive years, which may have led to the development of anthelmintic resistance. Closantel was used regularly during the 1990s on the three farms, but the substitute triclabendazole replaced closantel 15 years ago for the prevention and treatment of fasciolosis. All animals were last treated for GIN three months before the study.

To confirm the natural infection of the animals, fecal samples were collected from a randomly selected sample of 240 sheep on each farm, seven days before the beginning of the study. Samples were examined by coproscopy using the fecal flotation technique to detect strongylid eggs 22 . Briefly, 3 to $5 \mathrm{~g}$ samples of feces were collected directly from the rectum and then were transported in an ice-cooled box and stored at $4{ }^{\circ} \mathrm{C}$ until processed in the laboratory. The maximum interval between sampling and processing in the laboratory was $48 \mathrm{~h}$. Fecal egg counts were performed using the McMaster technique, with a detection level of 20 eggs per gram of feces, EPG ${ }^{22-25}$. The GIN load from the McMaster technique determined the selection of grazing sheep, and only sheep infected with more than 200 EPG were included in the study ${ }^{23}$. On all farms, fecal samples were collected the day the anthelmintic treatments were administered, and on days 14 and 21 after treatment.

On the three farms, male and female sheep, approximately 3 to 6 months in age and weighing 13 to $28 \mathrm{~kg}$ with more than 200 EPG, were randomly assigned to one of five experimental groups ( $n=28 /$ group). One additional untreated control group was established on each farm ( $n=28 /$ group). Two lambs that were three-months of age and had not received a previous anthelmintic treatment were included in the study because these animals shed more than 200 EPG when they were screened before treatment.

Sheep in the untreated group received a placebo of $30 \mathrm{ml}$ of water. In the experimental groups, single doses of anthelmintic drugs were orally administered as follows: fenbendazole at a dose of $10 \mathrm{mg} / \mathrm{kg}$ (FBZ); closantel at $5 \mathrm{mg} / \mathrm{kg}$ (CLOS); albendazole at $10 \mathrm{mg} / \mathrm{kg}$ (ABZ); closantel + fenbendazole at 5 and $10 \mathrm{mg} / \mathrm{kg}$, respectively (CLOS + FBZ); and closantel + albendazole at 5 and $10 \mathrm{mg} / \mathrm{kg}$, respectively (CLOS + ABZ). Active principles were kindly donated by PARFARM $\mathrm{S}$. A, Mexico City. Suspension batches of albendazole, fenbendazole and closantel were prepared by slowly adding weighed amounts of polyvinylpyrrolidone K-30 to a mixture of polypropylene glycol and cold sterile water with continuous stir- 
ring until a homogeneous suspension was obtained. On all farms, the anthelmintic drugs were used within a month, originated from the same batches and were stored in a cool, dry and dark place. Before drug administration, all animals were weighed.

\section{Larval culture}

To determine the species composition and the most frequent gastrointestinal nematode helminthofauna in the sheep, a pooled fecal culture from each farm was prepared. Approximately $50 \mathrm{~g}$ of pooled feces from each group of sheep was mixed with sawdust, pieces of sponge and water. Cultures in plastic containers were covered with foil and maintained moist in a cabinet for 12 days at $27^{\circ} \mathrm{C}$. Each culture was opened daily and mixed with a wooden spoon to increase oxygenation. When necessary, water was added. Third-stage larvae of $\mathrm{GIN}\left(\mathrm{L}_{3}\right)$ were recovered using the Baermann extraction technique for 12 hours ${ }^{22}$. The genus-level composition of the larval nematodes was determined by microscopic examination of the first 100 randomly selected $\mathrm{L}_{3}$ from the coproculture extractions, with the aid of taxonomic keys ${ }^{26}$.

\section{Fecal egg count reduction test}

For the fecal egg count reduction test (FECRT), the calculations to estimate the percentage mean reduction of egg counts with $95 \%$ confidence intervals were performed in an Excel spreadsheet created by Angus Cameron (AusVet Animal Health Services for the University of Sydney). Calculations were based on the RESOC FECRT analysis program (Version 2.0 CSIRO, Animal Health Research Laboratory, PARKSVILLE, 3052. University of Sydney) ${ }^{27}$. According to the World Association for the Advancement of Veterinary Parasitology guidelines, resistance to an anthelmintic class occurs when the percentage reduction in EPG after treatment is less than $95 \%$ and the lower limit of the $95 \%$ confidence interval is less than $90 \%$. When one of these two criteria is met, $\mathrm{AH}$ resistance is suspected $2,23,27,28$. Recently, the inclusion of the upper $95 \%$ confidence limit in the assessment of the anthelmintic resistance status was recommended because with this inclusion, the situations in which anthelmintic resistance is possible but not certain can be distinguished from those in which anthelmintic resistance is confirmed ${ }^{29}$.

\section{Statistical analyses}

The general percentage reduction in GIN eggs per gram of feces for the two time periods of 0-14 and 0-21 d was analyzed, and these reductions were used as endpoints. The design of the experiment was a two-factor complete block design; individuals were randomly assigned to groups (treatment $i=1,2,3,4,5,6$ ) on each farm, two sample times were examined $(k=14,21)$, and the different farms were used as blocks $(j=A, B, C)$. The endpoint general percentage reduction in GIN eggs per gram of feces data were normalized with arcsin transformation ( $\sqrt{ } p)$. Endpoint data were analyzed with a univariate general linear model. Differences among means were determined with Bonferroni tests. For the general linear mod$\mathrm{el}$, a threshold of $\mathrm{P}<0.01$ was used to reject the non-difference null hypothesis 
Table 1. Marginal means and $95 \% \mathrm{Cls}$ of the percent reduction of eggs per gram at 14 and 21 days after treatment of sheep ( $n=28$ per flock) with fenbendazole (FBZ), closantel (CLOS), albendazole (ABZ), closantel + fenbendazole

$(C L O S+F B Z)$ and closantel + albendazole (CLOS + ABZ) on three different farms $(A, B, C)$.

\begin{tabular}{|c|c|c|c|c|c|}
\hline \multirow{2}{*}{ Group } & \multirow{2}{*}{ Day } & \multirow{2}{*}{$\begin{array}{l}\% \text { EPG reduction } \\
\text { (Mean } \pm \text { SE) }\end{array}$} & \multicolumn{2}{|c|}{$95 \%$ Confidence interval } & \multirow{2}{*}{ Status } \\
\hline & & & Lower & Upper & \\
\hline \multirow[t]{2}{*}{ ALB } & 14 & $57.19 \pm 3.04^{a}$ & 50.78 & 63.61 & $\mathrm{R}$ \\
\hline & 21 & $57.62 \pm 3.04^{\mathrm{a}}$ & 51.20 & 64.03 & $\mathrm{R}$ \\
\hline \multirow[t]{2}{*}{ CLOS } & 14 & $86.71 \pm 3.04^{b}$ & 80.29 & 93.12 & $\mathrm{R}$ \\
\hline & 21 & $87.13 \pm 3.04^{b}$ & 80.71 & 93.54 & $\mathrm{R}$ \\
\hline \multirow[t]{2}{*}{ FBZ } & 14 & $63.00 \pm 3.04^{a}$ & 56.59 & 69.42 & $\mathrm{R}$ \\
\hline & 21 & $63.43 \pm 3.04^{a}$ & 57.01 & 69.84 & $\mathrm{R}$ \\
\hline \multirow[t]{2}{*}{$\mathrm{CLOS}+\mathrm{ALB}$} & 14 & $96.46 \pm 3.04^{b}$ & 90.05 & 102.88 & $\mathrm{~S}$ \\
\hline & 21 & $96.88 \pm 3.04^{b}$ & 90.47 & 103.30 & $\mathrm{~S}$ \\
\hline \multirow[t]{2}{*}{$\mathrm{CLOS}+\mathrm{FBZ}$} & 14 & $84.67 \pm 3.04^{b}$ & 78.25 & 91.08 & $\mathrm{R}$ \\
\hline & 21 & $85.09 \pm 3.04^{b}$ & 78.67 & 91.50 & $\mathrm{R}$ \\
\hline \multirow[t]{2}{*}{ CONTROL } & 14 & $-11.01 \pm 3.04^{c}$ & -17.42 & -4.59 & \\
\hline & 21 & $-10.59 \pm 3.04^{c}$ & -17.00 & -4.17 & \\
\hline
\end{tabular}

$\%$ EPG reduction = percentage reduction in eggs per gram

$\mathrm{Cl}=$ confidence interval

$\mathrm{R}=$ resistant

$\mathrm{S}=$ susceptible

Superscript letters indicate Bonferroni differences (Bonferroni $P<0.05)$ among treatments $\left(F_{5,10}=85.22 ; P=0.0001\right.$ ).

Differences were not significant in the comparisons of day 14 and $21\left(F_{1,5}=0.034 ; P=0.86\right)$.

between factors or for the interaction. A threshold of $\mathrm{P}<0.05$ was used for Bonferroni tests. Marginal means, standard errors and $95 \% \mathrm{Cl}$ were obtained with the least squares method. Analyses were performed with the IBM SPSS $20{ }^{\circledR}$ statistical software package. Additionally, the most frequent genera of GIN that occurred pre-treatment are presented.

\section{Results and discussion}

Based on the morphometric identification of larvae, Haemonchus spp., Cooperia spp. and Teladorsagia spp. were the most abundant genera on all farms before the administration of the five treatments. However, Trichostrongylus, Oesophagostomum, Chabertia, Nematodirus and Strongyloides were also detected.

Before the experiment, anthelmintic resistance was $1831.25 \pm 173.31 \mathrm{EPG}$ (fenbendazole group); $1760.41 \pm 56.71$ EPG (closantel group); $1689.58 \pm$ 142.56 EPG (albendazole group); $1410.41 \pm 193.78$ EPG (closantel + fenbendazole group); $1539.58 \pm 198.85$ EPG (closantel + albendazole group); and $1518.75 \pm 163.45$ EPG (control group). After experimental treatments, the control and treated groups were tested for resistance on days 14 and 21 (see Materials and Methods). Accordingly, susceptibility was confirmed for the closantel plus albendazole combination (CLOS + ABZ, Table 1) because the percentage GIN fecal egg output was reduced by $96.46 \pm 3.04 \%$ (day 14) and $96.88 \pm 3.04 \%$ (day 21). Resistance was demonstrated against fenbendazole (FBZ), closantel (CLOS), 


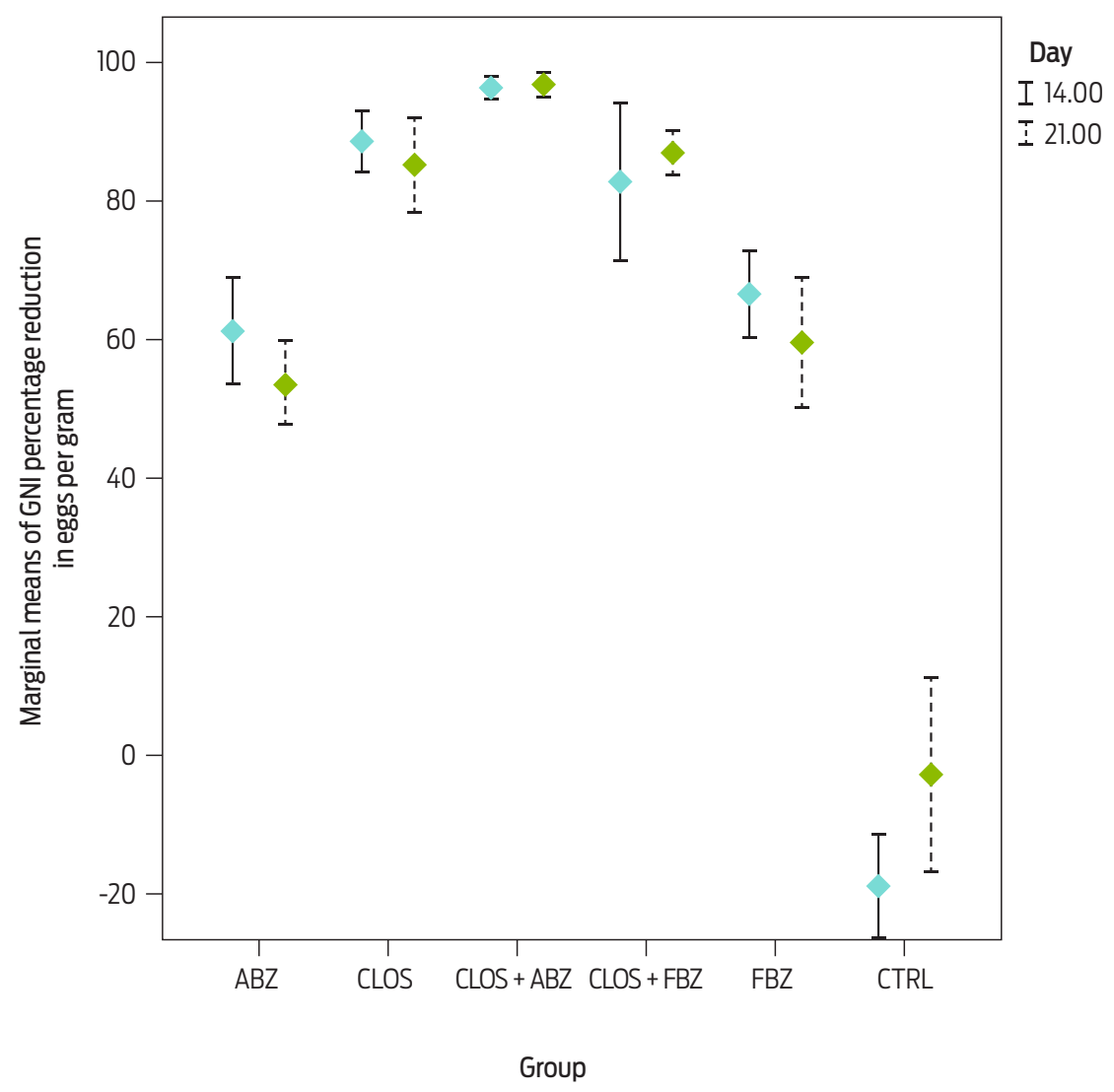

Figure 1. Marginal means \pm SD of the percentage reduction in egg count on days 14 and 21 after treatment of sheep on three farms ( $n=28$ per flock) with fenbendazole (FBZ), closantel (CLOS), albendazole (ABZ), closantel + fenbendazole (CLOS + FBZ) and closantel + albendazole (CLOS + ABZ).

albendazole (ABZ) and the combination CLOS + FBZ treatments because the mean percentage EPG reduction was $\leq 95 \%$, and the lower confidence limit of $\leq 90 \%$ on both sample days (14 and 21 days) was based on the FECRT and WAAVP guidelines ${ }^{23,28}$. On average, the fecal egg count in untreated sheep was 1850 EPG in Estado de Mexico, 1350 EPG in Puebla, and 1700 EPG in Morelos. Significant differences were observed for the group factor $\left(F_{5,10}=85.22 ; \mathrm{P}=0.0001\right)$ but not for the time period when samples were collected $\left(F_{1,17}=0.034 ; P=0.86\right)$ or for the group-block interaction $\left(\mathrm{F}_{10,17}=2.27 ; \mathrm{P}=0.066\right)$.

Although no differences were found between days 14 and 21, the WAAVP guidelines indicate that samples must be collected 8-10 or 14 days after treatment. The general marginal mean and standard error with a $95 \% \mathrm{Cl}$ on day 14 for the percent GIN reduction of EPG for each group are presented in Table 1. Figure 1 shows the arithmetic means \pm SD of these data. The advantage of the fecal egg count reduction test (FECRT) is that it can be used for all anthelmintic classes; thus, the FECRT was appropriate for the categorization of resistance in this study. Moreover, according to recent studies, corrections in formulas and models can ensure categorization of resistance in small flocks or herds when the parasite population is highly aggregated or when animals excrete low counts of eggs $24,30-33$. Based on the FECRT following WAAVP guidelines ${ }^{23}$, GIN were susceptible to the combination closantel plus albendazole. This result was expected because a mixture of two or 
more actives with different pharmacological properties but a similar spectrum can increase anthelmintic efficacy or delay the development of resistance ${ }^{34,35}$. This beneficial effect is particularly noted following oral administration of combinations of different anthelmintic classes 36,37 . Fitness costs are associated with resistant genotypes, and nematodes that carry multiple sets of resistance genes are less fit than those that are resistant to only one anthelmintic class ${ }^{38}$. Thus, the evidence continues to increase that the best approach for the efficient control of GIN with current compounds and to even slow the development of resistance is to formulate them as combinations because the survival of resistant genotypes is minimized 39,40 . Nevertheless, these results must be carefully considered; although control is provided by using anthelmintics containing multiple actives, parasite control also increases when high levels of refugia are maintained ${ }^{35}$.

Two questions remain to be answered: (1) What is the mechanism of action to explain the susceptibility of gastrointestinal nematodes to the combination of closantel plus albendazole? (2) Why are GIN resistant to the treatment with closantel plus fenbendazole? To explain the efficacy of closantel plus albendazole, ATP synthesis may be strongly reduced because of degenerative changes in the endoplasmic reticulum induced by albendazole ${ }^{41}$ and the suppression of succinate dehydrogenase and fumarate reductase activities by closantel ${ }^{42}$. However, this proposed mechanism requires further investigation. Additionally, compared with almost no uptake of fenbendazole ${ }^{43}$, the higher bioavailability of albendazole provides a plausible explanation for the higher efficacy of albendazole. The bioavailability of albendazole is higher than most benzimidazole derivatives, and the parent compound and the active metabolites undergo biliary excretion and accumulate in the gastrointestinal tube ${ }^{44}$. However, further studies are required to explain the differences in the efficacy of these compounds.

In geographical areas in which intensive sheep production requires the continuous use of antiparasitics, the patterns of anthelmintic resistance observed in this study are commonly reported $3,10,7,8,15,45$. However, studies investigating such patterns of resistance are rare in Mexico. Thus, to decrease the selection pressure that leads to the development of anthelmintic resistance in ruminants, approaches to nematode control in sheep flocks must be based on epidemiological studies, fecal examinations, nutrition strategies and targeted, selective treatments, as suggested previously $7,45,46$.

\section{Conclusions}

In sheep naturally infected with gastrointestinal nematodes, anthelmintic resistance was determined after the administration of either single drugs that have different mechanisms of action or a combination of these drugs; namely, albendazole, fenbendazole and closantel. Based on this study, the combination of closantel plus albendazole can be effective for the control of infections by resistant gastrointestinal nematodes. 


\section{Funding}

Funding from DGAPA PAPIIT IT200816 is gratefully acknowledged.

\section{Acknowledgements}

The authors are grateful to Juan Antonio Figueroa-Castillo and Aldo Bruno Alberti-Navarro for technical assistance.

\section{Conflicts of interest}

The authors declare that they have no conflicts of interest.

\section{Author contributions}

Yazmin Alcala-Canto: Contributed to the study design, carried out the experiments, collected fecal samples and administered anthelmintics, performed and supervised laboratory analysis, interpreted and discussed results, wrote and provided input to the manuscript and revisions.

Luis Ocampo Camberos: Contributed to the study design, results interpretation and discussion.

Héctor Sumano López: Contributed to the study design, analysis of data, results interpretation, discussion, supervised experimental procedures and provided input to the manuscript and revisions.

Lilia Gutiérrez Olvera: Collected fecal samples and administered anthelmintics, contributed to the preparation of the anthelmintic drugs, experimental design, analysis, discussion of results, wrote and provided input to the manuscript and revisions.

Graciela Tapia Pérez: Recommended the experimental design, performed all statistical data analysis and interpretation, and provided input to the manuscript.

All authors read and approved the final revised version of the manuscript.

\section{References}

1. Besier B. New anthelmintics for livestock: the time is right. Trends Parasitol. 2007;23(1):21-4. doi: 10.1016/j.pt.2006.11.004.

2. Encalada-Mena L, Tuyub-Solis H, Ramirez-Vargas G, Mendoza-de-Gives P, Aguilar-Marcelino L, Lopez-Arellano ME. Phenotypic and genotypic characterisation of Haemonchus spp. and other gastrointestinal nematodes resistant to benzimidazole in infected calves from the tropical regions of Campeche State, Mexico. Vet Parasitol. 2014(1873-2550):246-54.

3. Chan-Perez JI, Torres-Acosta JF, Rodriguez-Vivas RI, Villegas-Perez SL. Reduction of benzimidazole resistance in established Haemonchus contortus populations in goats using a single infection with a benzimidazole-susceptible isolate. J Helminthol. 2015;89(1475-2697):641-5.

4. Höglund J, Gustafsson K, Ljungström BL, Engström A, Donnan A, Skuce P. Anthelmintic resistance in Swedish sheep flocks based on a comparison of the results from the faecal egg count reduction test and resistant allele frequencies of the beta-tubulin gene. Vet Parasitol. 2009;161(1-2):60-8. doi: 10.1016/j. vetpar.2008.12.001.

5. Falzon LC, O'Neill TJ, Menzies PI, Peregrine AS, Jones-Bitton A, vanLeeuwen J, et al. A systematic review and meta-analysis of factors associated with anthelmint- 
ic resistance in sheep. Prev Vet Med. 2014;117(2):388-402. doi: 10.1016/j. prevetmed.2014.07.003.

6. Zvinorova PI, Halimani TE, Muchadeyi FC, Matika O, Riggio V, Dzama K. Breeding for resistance to gastrointestinal nematodes - the potential in low-input/ output small ruminant production systems. Vet Parasitol. 2016;225:19-28. doi: 10.1016/j.vetpar.2016.05.015.

7. Torres-Acosta JF, Mendoza-de-Gives P, Aguilar-Caballero AJ, Cuéllar-Ordaz JA. Anthelmintic resistance in sheep farms: update of the situation in the American continent. Vet Parasitol. 2012;189(1):89-96. doi: 10.1016/j.vetpar.2012.03.037.

8. Torres-Acosta JF, Molento M, Mendoza de Gives P. Research and implementation of novel approaches for the control of nematode parasites in Latin America and the Caribbean: is there sufficient incentive for a greater extension effort? Vet Parasitol. 2012;186(1-2):132-42. doi: 10.1016/j.vetpar.2011.11.053.

9. Hoste $\mathrm{H}$, Torres-Acosta JFJ. Non chemical control of helminths in ruminants: Adapting solutions for changing worms in a changing world. Vet Parasitol. 2011;180:144-54.

10. Molento MB, Fortes FS, Pondelek DA, Borges FeA, Chagas AC, Torres-Acosta JF, et al. Challenges of nematode control in ruminants: focus on Latin America. Vet Parasitol. 2011 ;180(1-2):126-32. doi: 10.1016/j.vetpar.2011.05.033.

11. Kaplan RM. Drug resistance in nematodes of veterinary importance: a status report. Trends Parasitol. 2004;20(10):477-81. doi: 10.1016/j.pt.2004.08.001.

12. Kaplan RM, Vidyashankar AN. An inconvenient truth: global worming and anthelmintic resistance. Vet Parasitol. 2012;186(1-2):70-8. doi: 10.1016/j. vetpar.2011.11.048.

13. Kupčinskas T, Stadalienè I, Šarkūnas M, Riškevičienè V, Várady M, Höglund J, et al. Prevalence of anthelmintic resistance on Lithuanian sheep farms assessed by in vitro methods. Acta Vet Scand. 2015;57:88. doi: 10.1186/s 13028-015-0179-y.

14. Rialch A, Vatsya S, Kumar RR. Detection of benzimidazole resistance in gastrointestinal nematodes of sheep and goats of sub-Himalyan region of northern India using different tests. Vet Parasitol. 2013;198(3-4):312-8. doi: 10.1016/j. vetpar.2013.09.018.

15. Torres-Acosta JF, Dzul-Canche U, Aguilar-Caballero AJ, Rodríguez-Vivas RI. Prevalence of benzimidazole resistant nematodes in sheep flocks in Yucatan, Mexico. Vet Parasitol. 2003;1 14(1):33-42.

16. Encalada-Mena LA, Duarte-Ubaldo El, Vargaz-Magana JJ, Garcia-Ramirez MJ, Medina-Hernandez RE. Prevalencia de parásitos gastroentéricos de canidos en la ciudad de Escarcega, Campeche, Mexico. Universidad y Ciencia. 201 1(2):209.

17. Silvestre A, Humbert JF. Diversity of benzimidazole-resistance alleles in populations of small ruminant parasites. Int J Parasitol. 2002;32(7):921-8.

18. Silvestre A, Leignel V, Berrag B, Gasnier N, Humbert JF, Chartiere $C$, et al. Sheep and goat nematode resistance to anthelmintics: pro and cons among breeding management factors. Vet Res. 2002;33(5):465-80. doi: 10.1051/ vetres:2002033.

19. Besier RB, Lyon J, Kieran PJ. The effect of moxidectin against benzimidazoleand levamisole-resistant nematodes of sheep in Western Australia. Aust Vet J. 1993;70(11):422-3.

20. Besier RB. Targeted treatment strategies for sustainable worm control in small ruminants. Trop Biomed. 2008;25(1 Suppl):9-17. 
21. Nunes R, dos Santos L, Bastianetto E, Andrade de Oliveira D, Alves B, Brasil $F$. Frequency of benzimidazole resistance in Haemonchus contortus populations isolated from buffalo, goat and sheep herds. Rev Bras Parasitol Vet.. 2013;22(4):548-53.

22. Figueroa CJA, Jasso VC, Liébano HE, Martínez LP, Rodríguez VRI, Zárate RJJ. Examen Coproparasitoscópico. In: Técnicas para el diagnóstico de parásitos con importancia en salud pública y veterinaria. DF, México: AMPAVE-CONASA;2015. $517 \mathrm{p}$.

23. Coles GC, Jackson F, Pomroy WE, Prichard RK, von Samson-Himmelstjerna $\mathrm{G}$, Silvestre $\mathrm{A}$, et al. The detection of anthelmintic resistance in nematodes of veterinary importance. Vet Parasitol. 2006;136(3-4):167-85. doi: 10.1016/j. vetpar.2005.11.019.

24. Levecke B, Rinaldi L, Charlier J, Maurelli MP, Bosco A, Vercruysse J, et al. The bias, accuracy and precision of faecal egg count reduction test results in cattle using McMaster, Cornell-Wisconsin and FLOTAC egg counting methods. Vet Parasitol. 2012;188(1-2):194-9. doi: 10.1016/j.vetpar.2012.03.017.

25. Sweeny JP, Robertson ID, Ryan UM, Jacobson C, Woodgate RG. Comparison of molecular and McMaster microscopy techniques to confirm the presence of naturally acquired strongylid nematode infections in sheep. Mol Biochem Parasitol. 2011;180(1):62-7. doi: 10.1016/j.molbiopara.2011.07.007.

26. van Wyk JA, Cabaret J, Michael LM. Morphological identification of nematode larvae of small ruminants and cattle simplified. Vet Parasitol. 2004;1 19(4):277306. doi: 10.1016/j.vetpar.2003.11.012.

27. CSIRO. Report of the working party for the Animal Health Committee of the Standing Committee on Agriculture; 1989. Contract No. 28.

28. Coles GC, Bauer C, Borgsteede FH, Geerts S, Klei TR, Taylor MA, et al. World Association for the Advancement of Veterinary Parasitology (WAAVP) methods for the detection of anthelmintic resistance in nematodes of veterinary importance. Vet Parasitol. 1992;44(1-2):35-44.

29. Lyndal-Murphy M, Swain AJ, Pepper PM. Methods to determine resistance to anthelmintics when continuing larval development occurs. Vet Parasitol. 2014;199(3-4):191-200. doi: 10.1016/j.vetpar.2013.11.002.

30. Dobson RJ, Hosking BC, Jacobson CL, Cotter JL, Besier RB, Stein PA, et al. Preserving new anthelmintics: a simple method for estimating faecal egg count reduction test (FECRT) confidence limits when efficacy and/or nematode aggregation is high. Vet Parasitol. 2012;186(1-2):79-92. doi: 10.1016/j. vetpar.2011.11.049.

31. Levecke B, Rinaldi L, Charlier J, Maurelli MP, Morgoglione ME, Vercruysse J, et al. Monitoring drug efficacy against gastrointestinal nematodes when faecal egg counts are low: do the analytic sensitivity and the formula matter? Parasitol Res. 2011;109(3):953-7. doi: 10.1007/s00436-011-2338-z.

32. McKenna PB. A comparison of faecal egg count reduction test procedures. N Z Vet J. 2006;54(4):202-3. doi: 10.1080/00480169.2006.36697.

33. McKenna PB. Further comparison of faecal egg count reduction test procedures: sensitivity and specificity. N Z Vet J. 2006;54(6):365-6. doi: 10.1080/00480169.2006.36726. 
34. Bartram DJ, Leathwick DM, Taylor MA, Geurden T, Maeder SJ. The role of combination anthelmintic formulations in the sustainable control of sheep nematodes. Vet Parasitol. 2012;186(3-4):151-8. doi: 10.1016/j.vetpar.2011.11.030.

35. Leathwick DM, Ganesh S, Waghorn TS. Evidence for reversion towards anthelmintic susceptibility in Teladorsagia circumcincta in response to resistance management programmes. Int J Parasitol Drugs Drug Resist. 2015;5(1):9-15. doi: 10.1016/j.jpddr.2015.01.001.

36. McKenna PB. The use of benzimidazole-levamisole mixtures for the control and prevention of anthelmintic resistance in sheep nematodes: an assessment of their likely effects. NZ Vet J. 1990;38(2):45-9. doi: 10.1080/00480169.1990.35614.

37. Leathwick DM, Miller CM, Sauermann CW, Candy PM, Ganesh S, Fraser K, et al. The efficacy and plasma profiles of abamectin plus levamisole combination anthelmintics administered as oral and pour-on formulations to cattle. Vet Parasitol. 2016;227:85-92. doi: 10.1016/j.vetpar.2016.07.031.

38. Leathwick DM. Managing anthelmintic resistance--parasite fitness, drug use strategy and the potential for reversion towards susceptibility. Vet Parasitol. 2013;198(1-2):145-53. doi: 10.1016/j.vetpar.2013.08.022.

39. Leathwick DM, Waghorn TS, Miller CM, Candy PM, Oliver AM. Managing anthelmintic resistance--use of a combination anthelmintic and leaving some lambs untreated to slow the development of resistance to ivermectin. Vet Parasitol. 2012;187(1-2):285-94. doi: 10.1016/j.vetpar.2011.12.021.

40. Learmount J, Taylor MA, Bartram DJ. A computer simulation study to evaluate resistance development with a derquantel-abamectin combination on UK sheep farms. Vet Parasitol. 2012;187(1-2):244-53. doi: 10.1016/j.vetpar.201 1.12.033.

41. Schmahl G, Benini J. Treatment of fish parasites. 11. Effects of different benzimidazole derivatives (albendazole, mebendazole, fenbendazole) on Glugea anomala, Moniez, 1887 (Microsporidia): ultrastructural aspects and efficacy studies. Parasitol Res. 1998;84(1):41-9.

42. Swan GE. The pharmacology of halogenated salicylanilides and their anthelmintic use in animals. J S Afr Vet Assoc. 1999;70(2):61-70.

43. Gokbulut C, Bilgili A, Hanedan B, McKellar QA. Comparative plasma disposition of fenbendazole, oxfendazole and albendazole in dogs. Vet Parasitol. 2007;148(3-4):279-87. doi: 10.1016/j.vetpar.2007.06.028.

44. McKellar QA, Coop RL, Jackson F. The pharmacokinetics of albendazole metabolites following administration of albendazole, albendazole sulfoxide and netobimin to one-month- and eight-month-old sheep. Int J Parasitol. 1995;25(10):1207-12.

45. Torres-Acosta JFJ, Sandoval-Castro CA, Hoste H, Aguilar-Caballero AJ, Cámara-Sarmiento R, Alonso-Díaz MA. Nutritional manipulation of sheep and goats for the control of gastrointestinal nematodes under hot humid and subhumid tropical conditions. Small Rumin Res. 2012;103(1):28-40. doi: 10.1016/j. smallrumres.2011.10.016.

46. Torres-Acosta JF, Molento M, Fau-Mendoza de Gives P, Mendoza de Gives P. Research and implementation of novel approaches for the control of nematode parasites in Latin America and the Caribbean: is there sufficient incentive for a greater extension effort? Vet Parasitol. 2012(1873-2550):132-42. 